\title{
Cataract-nephropathy-encephalopathy syndrome
}

INSERM

\section{Source}

INSERM. (1999). Orphanet: an online rare disease and orphan drug data base. Cataractnephropathy-encephalopathy syndrome. ORPHA:1380

Cataract - nephropathy - encephalopathy syndrome describes a lethal combination of manifestations including short stature, cong enital cataracts, encephalopathy with epileptic fits, and postmortem confirmation of nephropathy (renal tubular necrosis). The combination of cataract - nephropathy - encephalopathy has been described in 2 female infant children of first cousin parents. The infants did not survive beyond 4 and 8 months respectively. There have been no further descriptions in the literature since 1963. 